Canada's drug approval process may be based on clinical trials or "real world" trials (or both), ${ }^{2}$ but under the current policy, patients receiving a prescription for a new drug will be unaware of the full scope of the evidence. If it consists solely of data from randomized clinical trials, then patients ought to be informed that there may be limitations in detecting unmeasured or rare adverse outcomes that might appear later in a real world setting, in observational studies or in additional clinical trials.

The proposal by Eike-Henner Kluge that newly released drugs be given conditional licences until the outcomes of phase IV studies are known ${ }^{1}$ would ensure that health care professionals inform patients that the prescribed drug is still under review by Health Canada. Patients who decide to take the new drug (after being informed of the benefit-risk balance, the alternative options and their effectiveness, costs and uncertainties) should then be monitored for adverse effects and any such adverse outcomes reported to appropriately designated authorities.

From an ethical point of view, there are similarities between patients who participate in randomized controlled studies and those who participate in real world trials, since in both types of studies, drug efficacy and safety are still under review. Therefore, it seems to me that the ethical guidelines currently applied for the first group should also be applied to consumers of medications prescribed under conditional licences. ${ }^{4}$

\section{Joseph Erban}

Member, Clinical Ethics Committee

Sir Mortimer B. Davis - Jewish General Hospital

Montréal, Que.

\section{References}

1. Eggertson L. Drug approval system questioned in US and Canada. CMA7 2005;172(3):317-8.

2. Laupacis A, Paterson JM, Mamdani M, Rostom A, Anderson GM. Gaps in the evaluation and monitoring of new pharmaceuticals: proposal for a different approach [editorial]. CMA7 2003;169(11):1167-70.

3. Juni P, Nartey L, Reichenbach S, Sterchi R, Dieppe PA, Egger M. Risk of cardiovascular events and rofecoxib: cumulative meta-analysis. Lancet 2004;364:2021-9.

4. Tri-Council policy statement. Ethical conduct for research involving humans. Ottawa: Medical Research Council of Canada, Natural Sciences and Engineer- ing Research Council of Canada, Social Sciences and Humanities research Council of Canada; 2003 Jun. Available: www.pre.ethics.gc.ca/english /pdf/TCPS June2003_E.pdf(accessed 2005 Jun 2).

The opinions expressed here are solely those of the author and do not represent the views of the Clinical Ethics Committee or the Sir Mortimer B. Davis Jewish General Hospital.

DOI:10.1503/cmaj.1050064

\section{Psychological aftermath of abortion}

W illiam Fisher and associates, ${ }^{1}$ in their article on women undergoing repeat induced abortion, state, "Evidence also does not indicate that women seeking repeat abortion are psychologically maladjusted."

Although this statement is not directly connected to the main study reported by Fisher and associates, we feel that it might mislead readers about psychological problems after abortion. Consider the following material from the literature:

- A recent study sponsored by the College of Physicians and Surgeons of Ontario compared 41000 women who had undergone induced abortion with a similar number who had not undergone abortion ${ }^{2}$ and found 5 times more hospital admissions for psychiatric problems among the women who had had abortions. This short-term study was conducted at 3 months after the abortions and did not address long-term effects or problems among women who were not admitted to hospital after abortion.

- In a study reported in this journal in 2003, Reardon and colleagues ${ }^{3}$ found a significantly higher risk of psychiatric admissions among lower-income women who had undergone induced abortions.

- In the course of our own research, we have found numerous reports of significant problems among women who have had an abortion. For example, a study from Finland ${ }^{4}$ showed a 6-fold greater incidence of suicide among women who had had an induced abortion than among women with normal pregnancies. In fact, many of over 70 scientific articles that we reviewed for a recent publication $^{5}$ reported various degrees of psychological problems after abortion.

- Increasing numbers of postabortion counselling services are being developed in North America and around the world. The largest in the United States is Project Rachel, which has many chapters, including several in Canada. ${ }^{6}$ Thousands of women are being helped by these services, sometimes long after the abortion, but there are undoubtedly many more who do not go for help.

- The Healing Choice postabortion counselling service, which is prochoice, estimates that at least $10 \%$ of women who have undergone an abortion need counselling for psychological problems associated with the procedure. ${ }^{7}$

On the basis of this evidence we can conclude that many women suffer problems after abortion. Given that follow-up after abortions is often lacking or short-term only, further research is needed in this area. Even if just 10\% of women who have had an abortion are experiencing these problems, this represents a substantial public health issue, considering that each year more than 100000 abortions are performed in Canada. ${ }^{8}$

\section{L.L. deVeber}

Professor Emeritus

University of Western Ontario

London, Ont.

Ian Gentles

Professor of History

York University

Toronto, Ont.

\section{References}

1. Fisher WA, Singh SS, Shuper PA, Carey M, Otchet F, MacLean-Brine D, et al. Characteristics of women undergoing repeat induced abortion. CMA7 2005;172(5):637-41.

2. Ostbye T, Wenghofer EF, Woodward CA, Gold G, Craighead J. Health services utilization after induced abortions in Ontario: a comparison between community clinics and hospitals. Am 7 Med Qual 2001;16(3):99-106.

3. Reardon DC, Cougle JR, Rue VM, Shuping MW, Coleman PK, Ney PG. Psychiatric admissions of low-income women following abortion and childbirth. CMA7 2003;168(10):1253-6.

4. Gissler M, Hemminki E, Lonnquist J. Suicides after pregnancy in Finland, 1987-94: register linkage study. BM7 1996;313(7070):1431-4.

5. Ring-Cassidy E, Gentles I. Women's bealth after 
abortion: the medical and psychological evidence. 2nd ed. Toronto: deVeber Institute for Bioethics and Social Research; 2003.

6. Thorn V. Project Rachel: faith in action, a ministry of compassion and caring. In: Mannion $M$, editor. Post abortion aftermath. Kansas City (MO): Sheed and Ward; 1994. p. 144-63.

7. Depuy C, Dovitch D. The healing choice: your guide to emotional recovery after abortion. New York: Fireside; 1997. p. 58.

8. Induced abortions by area of residence of patients (hospitals and clinics). Ottawa: Statistics Canada; 2005 Mar 30. Available: www40.statcan.ca/101 /cst01/health40a.htm (accessed 2005 May 13).

DOI:10.1503/cmaj.1050079

\section{[Two of the authors respond:]}

$\mathrm{C}$ ommenting on our study of the characteristics of women undergoing repeat induced abortion, ${ }^{1}$ L.L. deVeber and Ian Gentles imply that termination of pregnancy causes psychological problems. However, pre-existing differences between women who seek abortion and those who carry pregnancies to term are considerable and may account for differences in psychological status after abortion or delivery. A relevant comparison would assess psychological distress experienced by women seeking and obtaining an abortion and those seeking but denied pregnancy termination. Moreover, a full discussion of the possible consequences of abortion would include consideration of the considerable morbidity and mortality associated with illegal abortion. ${ }^{2}$

In a $C M A 7$ commentary, Major ${ }^{3}$ reminded us that "health providers and policy-makers [must] base their conclusions [about the effects of abortion] on reputable scientific research that is methodologically rigorous, conceptually sound and free from ideological bias."

The research cited by deVeber and Gentles, however, fails to meet this standard. For example, although Ostbye and associates ${ }^{4}$ showed a greater number of hospital admissions for psychiatric problems among women who have had abortions, the most significant predictor of this finding was a history of pre-abortion psychiatric admission (odds ratio 6.58, confidence interval 2.46-17.64). Similarly, although Gissler and colleagues ${ }^{5}$ related abortion to increased risk of suicide, they clearly stated that no conclusion about cause and effect could be made and that the associa- tion might be due to common risk factors for both suicide and abortion.

Reardon and collaborators ${ }^{6}$ also showed a greater association between abortion and psychiatric admission among low-income women who had had an induced abortion than among women who carried their pregnancy to term. That study had a number of limitations, however, including lack of information regarding psychiatric history earlier than 1 year before abortion or delivery. On the basis of Canadian findings for psychiatric admissions before abortion, ${ }^{4}$ it may be that greatly elevated rates of psychiatric problems precede abortion experience. Commenting on the study by Reardon and collaborators, ${ }^{6}$ Major ${ }^{3}$ noted that " $\mathrm{Al}$ though it is possible that abortion leads to psychiatric problems, it is just as plausible that the direction of causality is reversed, namely, that psychiatric problems cause women who become pregnant to feel less capable of raising a child and to terminate their pregnancy."

Abortion continues to be a controversial area of research. There is no causal evidence that abortion alone elevates the risk of psychiatric admission. Observational evidence of such an association may be readily interpreted as resulting from confounding pre-existing factors.

Sukhbir S. Singh

Department of Obstetrics and Gynaecology

William A. Fisher

Department of Psychology

Department of Obstetrics and

Gynaecology

University of Western Ontario

London, Ont.

\section{References}

1. Fisher WA, Singh SS, Shuper PA, Carey M, Otchet F, MacLean-Brine D, et al. Characteris- tics of women undergoing repeat induced abortion. CMA7 2005;172(5):637-41.

2. Van Look PF, Cottingham JC. Unsafe abortion: an avoidable tragedy. Best Pract Res Clin Obstet Gynaecol 2002;16:205-20.

3. Major B. Psychological implications of abortion - highly charged with rife and misleading research [editorial]. CMA7 2003;168(10):1257-8.

4. Ostbye T, Wenghofer EF, Woodward CA, Gold G, Craighead J. Health services utilization after induced abortions in Ontario: a comparison between community clinics and hospitals. $\mathrm{Am} \mathcal{F}$ Med Qual 2001;16(3):99-106.

5. Gissler M, Hemminki E, Lonnquist J. Suicides after pregnancy in Finland, 1987-94: register linkage study. BM7 1996;313(7070):1431-4.

6. Reardon DC, Cougle JR, Rue VM, Shuping MW, Coleman PK, Ney PG. Psychiatric admissions of low-income women following abortion and childbirth. CMA7 2003;168(10):1253-6.

DOI:10.1503/cmaj.1050145

\section{Staffing levels for long-term care}

$A$ s an officer of the BC Care 1 Providers Association (a provincial association representing both private and nonprofit facilities providing services to more than 10000 residents in British Columbia), I read with interest the article by Margaret McGregor and associates about staffing levels at longterm care facilities. ${ }^{1}$

Unfortunately, the numbers of direct care hours of staff time per resident day reported in the article (e.g., in Table 1) appear suspect. The information on staffing levels was taken from essential service designations of the British Columbia Labour Relations Board, but in all cases the values appear unreasonably high. They are certainly higher than the levels of staffing possible through funding received from government or health authorities. ${ }^{2}$ For example, the time for direct care in intermediate and extended care not-for-profit facilities is 